\title{
Vorbemerkung für den Benutzer
}

Die im Handbuch aufgenommenen Orte sind in alphabetischer Reihenfolge angeordnet und mit Bezirks- und Kreisangabe sowie mit einem Hinweis auf den amtlichen Inventarband versehen. In der alphabetischen Anordnung sind $\ddot{a}, 0 ̈$ und ü wie ae, oe und ue behandelt. Nicht mehr selbständige Gemeinden erscheinen jeweils unter dem Ort, dem sie eingemeindet sind. Entsprechende Verweisungen auf diese Ortsteile sind der alphabetischen Reihenfolge eingeordnet. Maßgebend war das von der Staatlichen Zentralverwaltung für Statistik herausgegebene Verzeichnis der Gemeinden und Ortsteile der Deutschen Demokratischen Republik, Stand I. Januar I962.

Ortschaften mit der amtlichen Bezeichnung „Bad“ sind nur unter dem Ortsnamen angeordnet.

Die Beschreibung nichterhaltener Denkmäler, soweit sie aufgenommen wurden, steht in cckiger Klammer.

Als Anhang sind dem Band angefügt ein Ortsverzeichnis, geordnet nach Bezirken und Kreisen, ein Verzeichnis der amtlichen Inventare der Kunstdenkmäler sowie ein Künstlerregister. 
